\title{
Especialização produtiva e retornos associados para os produtores de leite
}

João Batista da Luz Souza*

Alexandre Florindo Alves*

RESUMO - O estudo tem o objetivo de refletir sobre impactos normativos e de estímulos industriais sobre a pecuária leiteira. Para tanto, foram colhidas na literatura referências às principais transformações ocorridas no Sistema Agroindustrial do Leite no período recente e como aspectos, principalmente tecnológicos, são necessários para manter a atividade viável do ponto de vista econômico e técnico. O reflexo disso é uma constatação de que a especialização dos produtores constitui elemento fundamental tanto para a adequação às novas realidades quanto para a ampliação da produção e maior inserção no mercado.

Palavras-chave: Leite. Mudanças institucionais. Especialização. Tecnologia.

\section{INTRODUÇÃO}

A pecuária leiteira é uma atividade tradicional e de grande importância para economia brasileira. Após a década de 1990, houve uma série de transformações que promoveram uma reestruturação do Sistema Agroindustrial do Leite (SAL). Estas mudanças impactaram com maior intensidade na pecuária leiteira - produtores - que estão sendo obrigados a se adequar a um arcabouço institucional que é a Instrução Normativa 51 (IN51) e as exigências do mercado, impostas pela indústria.

Perante este quadro, o objetivo do presente estudo é evidenciar como a IN51 e os estímulos oferecidos pela indústria podem ser utilizados como uma estratégia para a ampliação da produção, maior inserção no mercado e ampliação da geração de renda para os produtores e, com isso, gerar possibilidade de manutenção do produtor na atividade.

Para que se possa entender o SAL e o seu desenvolvimento na atualidade são necessários resgatar e entender as principais transformações que este vem sofrendo nas duas últimas décadas. Para isso, buscou-se realizar uma síntese destas transformações, com o objetivo de descrever o ambiente nos quais se encontram os diferentes atores e os desdobramentos destas mudanças e a partir dai mostrar as principais estratégias associadas à atuação do produtor com

\footnotetext{
* Mestre pelo Programa de Pós-Graduação em Ciências Econômicas da Universidade Estadual de Maringá (PCE/UEM). É professor assistente do Departamento de Economia da mesma instituição. Endereço eletrônico: jblsouza@yahoo.com.br.

** Doutor em economia aplicada pela Escola Superior de Agricultura "Luiz de Queiroz" da Universidade de São Paulo (ESALQ/USP). É professor associado do Departamento de Economia da Universidade Estadual de Maringá (UEM). Endereço eletrônico: afalves@uem.br.
} 
a especialização na atividade leiteira.

\section{AS TRANSFORMAÇÕES NO SISTEMA AGROINDUSTRIAL DO LEITE (SAL)}

O sistema agroindustrial é um instrumento analítico que proporciona um arcabouço teórico e uma maior clareza para que se possa identificar gargalos de ordem comercial, econômica, tecnológica, logística, legal, entre outras, e também é importante como uma ferramenta de gestão empresarial. Batalha e Silva (2008, p. 03) observaram que em uma relação sistêmica todos os segmentos devem ser eficientes. Nas palavras dos autores, "a competitividade sustentada de uma empresa somente pode ser construída no âmbito de um sistema igualmente competitivo no seu conjunto”. Resta então a todos os agentes econômicos que interagem neste sistema buscar uma maior eficiência, se adequando à nova realidade que o mundo globalizado impõe.

Atualmente o Brasil está entre os principais países produtores de leite. É o segundo maior produtor de leite das Américas e ocupou a sexta posição no mundo no ano de 2007, com uma produção de 25.327 bilhões de litros, o equivalente a 4,5\% da produção mundial (EMBRAPA, 2010).

Em parte, esta posição do Brasil no ranking da produção mundial do leite é consequência de uma série de eventos que ocorreram na década de 1990 e que promoveram uma ruptura com o ambiente institucional na qual o SAL se amparava nos últimos 45 anos, havendo três mudanças principais, que foram: i) o fim da intervenção do Estado na regulação dos preços; ii) a quebra das barreiras às importações; e iii) o fim da intervenção do Estado na regulação dos estoques. Isso fez com que as relações que antes norteavam os relacionamentos entre os atores do sistema agroindustrial, ou seja, entre consumidores, produtores e indústria, fossem redefinidas. Para Souza (2007a, p.32) "até hoje essas relações ainda não foram claramente redefinidas e estabilizadas, o que ainda tem trazido esse processo de reestruturação até os dias atuais".

As mudanças no ambiente institucional intensificaram a concorrência e a principal implicação destas mudanças foi a sinalização do mercado de que a permanência no sistema está cada vez mais condicionada à profissionalização e especialização na atividade. Para Dürr (2006) a qualidade do leite in natura passou a ser o melhor termômetro das transformações que ocorreram e vêm ocorrendo no setor, tendo em vista que a conquista da qualidade do leite só acontece mediante a profissionalização do sistema como um todo.

Com a abertura do mercado para a importação de produtos lácteos, o consumidor se deparou com uma maior diversidade de produtos e preços competitivos. Isso fez com que o consumidor se tornasse mais exigente em relação à qualidade dos produtos, emitindo assim informações que influenciaram o fluxo de produtos e serviços através de todo o sistema. Outros 
fatores como as responsabilidades sociais e ambientais também passam a ser valorizados. Com isso, o consumidor passa a exigir mais informações sobre os produtos que estão consumindo, maior transparência em relação às origens e o sistema produtivo adotado.

Nesta nova realidade, além de produzir bem e com menores custos é necessário produzir com qualidade, mas há que se questionar o que se entende por qualidade, se não havia uma legislação que estabelecesse normas e padrões para tal. Este problema foi equacionado com o Programa Nacional de Melhoria da Qualidade do Leite (PNMQL), criado em 1997 pelo Ministério da Agricultura Pecuária e Abastecimento (MAPA), que veio para tentar mudar a forma de se produzir leite no Brasil, a fim de determinar novas variáveis de avaliação da qualidade do leite para que a população possa consumir produtos lácteos mais seguros, mais nutritivos e saborosos.

É importante observar que a aquisição de um produto saudável para o consumo humano depende, em linhas gerais, das condições da ordenha, do seu manejo, das instalações, do armazenamento a temperaturas adequadas, do transporte até a indústria, das condições de recepção e do processamento, entre outros. Ao longo de todo este processo há vários pontos críticos; com isso, o PNMQL promoveu uma reformulação da legislação, procurando regulamentar o setor em relação às normas e padrões de qualidade, criando então a IN51, publicada em de 18 de setembro de 2002.

A normativa promoveu uma maior especialização do SAL, impactando de forma mais veemente o sistema produtivo e mais ainda o pequeno produtor. Dentre os principais benefícios da IN51 estão: i) elevar o padrão de qualidade do leite brasileiro, abrindo caminho para sua exportação; ii) maior segurança alimentar para o consumidor dos produtos lácteos; iii) maior rentabilidade para a indústria; e iv) menos problemas sanitários para o produtor.

A partir destas mudanças alguns produtores passaram a buscar sistemas de produção que sejam dinâmicos, modernos e competitivos. Jank e Galan (1999) definiram estes produtores como se segue:

[...] aqueles que têm como atividade principal a produção de leite, obtida a partir de rebanhos leiteiros especializados e outros ativos específicos para este fim, tendo investido em know-how, tecnologia, economias de escala e até alguma diferenciação do produto (a exemplo do leite tipo A e B). Há também aplicação de recursos financeiros em elementos de incremento da produção de leite em termos de volume e qualidade, como vacas especializadas de raças europeias, alimentos concentrados (farelo de soja, fubá de milho, polpa cítrica, etc.), alimentos volumosos (pastagens, forrageiras de alta produção, silagem, fenação, etc.), equipamentos de ordenha, resfriadores de leite, etc. (JANK; GALAN, 1999, p.190). 
Em algumas localidades este processo de especialização vem promovendo a exclusão de alguns produtores que não quiseram ou que não conseguiram se especializar na atividade por não possuírem recursos para se adequarem às novas normas produtivas, tendo assim que buscar novas alternativas econômicas que melhor se ajustem a sua realidade. Esta é uma das principais conclusões de autores como Jank e Galan (1999), Figueira e Belik (1999), Ferrari et al. (2005), Paes (2007) e Souza (2010).

A partir do Censo Agropecuário do IBGE (1996 - 2006) é possível observar um indício desta realidade. No Brasil houve uma queda no número de propriedades que se dedicavam à produção de leite, que chegou a 25,9\%. Em contraste, com a queda do número de produtores, houve uma elevação da produção em 19,5\%. Esta elevação da produção é fruto da busca do produtor pela especialização na atividade, o que se refletiu na maior produtividade, que se elevou em $62 \%$ no mesmo período.

\section{RETORNOS ASSOCIADOS À ESPECIALIZAÇÃO PRODUTIVA}

Este processo de reestruturação do SAL procurou compensar as décadas de atraso tecnológico em poucos anos. Neste processo a indústria passou a incentivar o incremento da produção de leite em termos de volume, qualidade e menor irregularidade da oferta ao longo do ano. Estes elementos são essenciais para a competitividade e desenvolvimento da indústria, que tem a possibilidade de elevar consideravelmente os ganhos através de ações que venham estimular estes fatores.

Em complemento a esta demanda do mercado e devido às próprias necessidades de modernização da legislação vigente em termos que segurança do alimento foi criada a IN51, que exige uma série de atributos de qualidade e para isso é necessária a inovação tecnológica da propriedade rural.

Neste sentido, o investimento na especialização produtiva, além de trazer um maior rendimento para o produtor através do maior volume de produção e das economias de escala geradas, gera a possibilidade de alavancar o rendimento da atividade através de ágio nos preços pagos pela indústria em função do volume, qualidade, e menor variação sazonal.

A qualidade da matéria-prima é apontada como um dos principais pontos críticos para a segurança alimentar da população consumidora e também para a competitividade da indústria nacional. A indústria foi o elo do sistema que foi mais beneficiado com a melhoria da qualidade do leite promovida pela IN51.

Segundo Souza (2007b), para a indústria a melhoria da qualidade do leite promove aumento da segurança alimentar, redução de perdas, aumento da vida de prateleira dos lácteos, 
agregação de valor aos produtos, uso seletivo da matéria prima, viabilização da exportação e redução de custos devido a: i) maior produtividade da matéria-prima por produtos acabados; ii) maior produtividade dos equipamentos; iii) menor necessidade de realizar manutenção ou troca de equipamentos; iv) maior produtividade da mão de obra; e v) diminuição dos gastos com aditivos para estabilização do leite.

Para Dürr (2006), apesar da qualidade dos produtos lácteos depender de um esforço conjunto do SAL, cabe à indústria de laticínios a condução do processo. Na Tabela 1, há algumas ações que podem ser canalizadas pela indústria para acelerar a melhoria da qualidade do leite.

TABELA 1 - GARGALOS E AÇÕES QUE PODEM SER IMPLANTADAS PELA INDÚSTRIA

\begin{tabular}{l|l}
\hline \multicolumn{1}{c|}{ Gargalos } & \multicolumn{1}{c}{ Ações da indústria } \\
\hline $\begin{array}{l}\text { Elevada contagem bacteriana } \\
\text { no leite in natura refrigerado }\end{array}$ & $\begin{array}{l}\text { Rígido controle da temperatura do leite na coleta; } \\
\text { Orientação técnica sobre higiene na ordenha, refrigeração, limpeza e manutenção } \\
\text { de equipamentos; } \\
\text { Treinamento e comprometimento dos transportadores; } \\
\text { Adoção de sistema de advertências e penalidades no preço do leite. }\end{array}$ \\
\hline $\begin{array}{l}\text { Elevada contagem de células } \\
\text { somáticas no leite in natura } \\
\text { refrigerado }\end{array}$ & $\begin{array}{l}\text { Orientação técnica sobre prevenção da mastite; } \\
\text { Adoção de sistema de advertências e penalidades no preço do leite. }\end{array}$ \\
\hline $\begin{array}{l}\text { Presença de resíduos de } \\
\text { antimicrobianos }\end{array}$ & $\begin{array}{l}\text { Orientação técnica sobre prevenção da mastite e controle de resíduos; } \\
\text { Uso de métodos de detecção de resíduos antimicrobianos sensíveis a diferentes } \\
\text { tipos de antibióticos, uma vez que no Brasil se permite a administração de diferen- } \\
\text { tes grupos de drogas; } \\
\text { Adoção de sistema de penalidades envolvendo preço do leite e descarte de cargas } \\
\text { condenadas. }\end{array}$ \\
\hline $\begin{array}{l}\text { Baixos teores de sólidos no } \\
\text { leite in natura refrigerado }\end{array}$ & $\begin{array}{l}\text { Orientação técnica sobre nutrição animal; } \\
\text { Rígido controle de fraudes (água, soro, desnate); } \\
\text { Adoção de sistema de bonificações pelos sólidos no preço do leite. }\end{array}$ \\
\hline $\begin{array}{l}\text { Adoção de um programa de roteirizarão da coleta do leite que impeça o transpor- } \\
\text { Integrado de melhoria da } \\
\text { qualidade do leite }\end{array}$ & $\begin{array}{l}\text { Terceirização da coleta de amostras nas propriedades para profissionais desvincu- } \\
\text { lados dos transportadores; } \\
\text { Classificação dos produtores em função da qualidade do leite para a destinação da } \\
\text { matéria prima de acordo com as necessidades industriais; } \\
\text { Criação de um sistema de divulgação rápida dos dados de qualidade para que } \\
\text { ações corretivas sejam adotadas no tempo certo; } \\
\text { Implantação do sistema APPCC em todas as etapas do processo produtivo. }\end{array}$ \\
\hline FONTE: Extrádo de
\end{tabular}
FONTE: Extraído da pesquisa de Dürr (2006, p. 94).

Neste quadro é possível visualizar diversas ações da indústria que podem promover a maior rentabilidade da atividade para o produtor. A orientação técnica em relação à higiene, nutrição e sanidade animal, oferecendo condições para o produtor se adequar aos padrões de qualidade exigidos pelo mercado. Já a adoção de sistema de bonificações e penalidades de acordo com a qualidade do leite, com isso o produtor que vem buscando se especializar na atividade pode ter um incremento no preço do seu produto. E a classificação dos produtores em função da qualidade do leite para a destinação da matéria-prima de acordo com as necessidades industriais.

A indústria tem a possibilidade de elevar consideravelmente sua capacidade compe- 
titiva e também melhorar a credibilidade da empresa junto a organizações privadas, governamentais e consumidores. O estímulo financeiro por parte da indústria para o aprimoramento da qualidade do leite traz benefícios tanto para a própria indústria como para os produtores e para o mercado consumidor.

A especialização dos produtores de leite na atividade também pode contribuir na minimização da variação sazonal da produção de leite. Desta forma, o produtor tem condições de manter uma renda mais constante e aproveitar períodos de alta dos preços. Isso por que a produção de leite de modo geral pode ser dividida, em produção na estação seca ${ }^{1}$ e das águas ${ }^{2}$. Fazendo uma analogia com a produção agrícola, a produção do leite tem uma safra que corresponde ao período das águas e entressafra que corresponde ao período da seca. $\mathrm{Na}$ seca ou na entressafra da produção do leite há uma queda na captação do leite pelos laticínios, sendo que esta queda é fruto da redução da oferta do leite pelos produtores.

De forma geral, Clemente e Hespanhol (2008) observaram que grande parte da alimentação do rebanho bovino no Brasil está associada às pastagens e forragens extensivas tropicais que concentram aproximadamente $80 \%$ nas estações chuvosas, coincidindo assim com maior oferta dos produtores de leite. Já no período da entressafra ocorre o inverso, há redução das pastagens tropicais, menor oferta e maior remuneração aos preços pagos ao produtor. A produção sofre uma variação que pode ser considerada diretamente proporcional à variação na precipitação de chuvas de cada período.

No período da estiagem os pastos se tornam secos, fibrosos, de baixos valores nutritivos e cada vez mais escassos. A energia que antes era destinada a manter o animal e para a produção do leite, com um regime alimentar mais restritivo, prioriza a subsistência do animal e a produção do leite cai. Segundo Mezzadri (2009), a escassez de pastagens no período da entressafra provoca uma queda entre $25 \%$ e $30 \%$, em média, da produção leiteira de rebanho criado extensivamente.

Desta forma, o produtor que investe no fornecimento de volumoso ${ }^{3}$ de boa qualidade, alimentos concentrados ${ }^{4}$ ou ao menos em sistemas de partejo, apesar de incorrer em maiores custos tem a oportunidade de obter um maior rendimento no período da entressafra da produção.

$1 \mathrm{Na}$ estação da seca ocorre uma diminuição ou até, dependendo das condições, a suspensão da produção leiteira.

$2 \mathrm{Na}$ estação das águas, mesmo sem nenhum tipo de tratamento especial, como é o caso do sistema a pasto, as vacas oferecem um bom rendimento.

3 Pasto, cana-de-açúcar com ureia, silagem, feno, etc.

4 Rações comerciais, suplementos protéicos, vitamínicos e minerais e resíduos ou subprodutos agroindustriais - caroço de algodão, polpa cítrica, farelos de cereais, etc. 
Existe ainda a possibilidade de explorar as economias de escala. Para Lootty e Szapiro (2002), as economias de escala estão associadas de modo geral a dois tipos de fonte: as economias de escala reais e economias de escala pecuniárias. A última ocorre quando há uma redução do preço dos insumos, de forma que há uma redução nos custos, mas não em resposta às mudanças reais no processo produtivo. Na pecuária leiteira, pode-se pensar na compra conjunta de insumos como ração e suplemento mineral, o que poderia impactar negativamente os custos de produção.

Já as economias de escala reais ocorrem quando há uma redução na quantidade de fatores produtivos utilizados em termos proporcionais em reação a um aumento da produção. Ou seja, embora a produção esteja crescendo, a quantidade de insumos não cresce na mesma proporção e sim, em uma proporção inferior ao acréscimo da produção.

Na pecuária leiteira pode-se citar como exemplo a produção a pasto. A quantidade de animais por hectare depende de uma série de fatores como a raça dos animais, o tipo de pasto, a produtividade do solo, fatores climáticos, entre outros. Levando em conta estes fatores pode-se considerar um número máximo de animais. Se o número de animais for inferior a este valor de referência, há a possibilidade de haver economias de escala com a adição de animais na pastagem. Neste caso a curva de custo médio irá decrescer inicialmente até atingir o seu ponto de mínimo onde é operado ao nível ótimo. Após este ponto há uma elevação de custos refletindo a existência de deseconomias de escala.

As economias de escala foram trabalhadas por Lopes (2006), para um grupo de produtores, onde os resultados evidenciam que estes buscam maior eficiência produtiva e que, ainda, possuem possibilidades de ganho no que se refere à melhor combinação, alocação e aproveitamento dos recursos gerenciais e produtivos.

Ficou evidente a ocorrência de ganhos com a escala de produção, tendo em vista a redução dos custos médios para maiores níveis de produção, bem como os indicadores de rendimentos à escala crescentes e de economias de escala, indicando ganhos com o crescimento da produção. Os gastos com fatores de produção resultaram em maior volume de produção. (LOPES, 2006, p. 66).

Na mesma linha de trabalho, Gomes (2006) observou que o crédito é um fator de grande importância para a rentabilidade da pecuária leiteira. Onde os maiores produtores possuem facilidades de acesso ao crédito como juros e prazos maiores, possibilitando assim o investimento, e aproveitamento das economias de escala, podendo evoluir para uma escala ótima. 
A partir do trabalho de Lootty e Szapiro (2002), é possível observar três principais fontes de economias de escala, mas fazendo uma ligação com a pecuária leiteira:

- Ganhos de especialização - que é a redução do custo médio decorrente do aumento da produção. No caso da pecuária leiteira a elevação da produção mediante a especialização do produtor na atividade gera maior produtividade e menores custos de produção;

- Indivisibilidade técnica - se relaciona com o tamanho dos equipamentos; a subutilização de um equipamento pode servir para uma futura expansão produtiva. Esta fonte de economias de escala pode ser pensada tanto em relação a pastagens como para resfriadores e ordenhadeiras. Ou seja, os fatores de natureza tecnológica também propiciam a ocorrência de economias de escala;

- Economias relacionadas à lei dos grandes números - quanto maior for o tamanho da planta produtiva, menor será o custo pensando em termos proporcionais. Um produtor que cuida de uma vaca leiteira é mais produtivo, por exemplo, ao cuidar de cinco, não implicando em maiores custos.

Gomes (1996 apud Lopes, 2006) apontou a produtividade como fator de condução à economia de escala. O autor constatou relação direta entre os maiores ganhos dos sistemas de exploração mais produtivos relacionados a custos médios de produção de leite menores. Esta relação indicou que, com o crescimento da produtividade das vacas ordenhadas, promove-se resposta significativa na redução do custo por litro de leite, implicando assim em melhor lucratividade para o produtor, que tem a sua margem de lucro ampliada.

\section{CONCLUSÃO}

As mudanças institucionais e de mercado promoveram e vem promovendo uma reestruturação do SAL e a maior especialização dos produtores na pecuária leiteira. Desta forma, muitos produtores estão sendo obrigados a deixar a atividade por não se adequarem a esta nova realidade.

Contudo, os produtores que buscam e conseguem se especializar na atividade podem explorar algumas estratégias como os incentivos fornecidos pela indústria na questão da qualidade, na diminuição da variação sazonal da produção e no aproveitamento das economias de 
escala. Estes fatores podem promover a ampliação da produção e maior inserção ao mercado, sendo relevante ainda na negociação de preços com os compradores (indústria). Desta forma, a reestruturação do SAL, embora tenha impactado negativamente muitos pequenos produtores, promoveu a modernização do setor.

\section{REFERÊNCIAS}

BATALHA, M. O.; SILVA, A. L. Gerenciamento de sistemas agroindustriais: definições, especificidades e correntes metodológicas. In: BATALHA, M. O. (org). Gestão agroindustrial: GEPAI - Grupo de Estudos e Pesquisas Agroindustriais. São Paulo: Atlas, 2008.

CLEMENTE, E. C.; HESPANHOL, A. N. Reestruturação da cadeia produtiva do leite: a especialização do produtor é a solução? In: $4^{\circ}$ Encontro Nacional de Grupos de Pesquisa - ENGRUP, São Paulo, p. 205-225, 2008.

DURR, J. W. Controle de qualidade e aumento da competitividade da indústria láctea. In: MARTINS, C. E. et al. (Org.). Tendências e avanços do agronegócio do leite nas Américas: Industrialização. Juiz de Fora: Embrapa Gado de Leite, 2006, v.1, p. 81-94.

FERRARI, D. L. et al. Agricultores familiares, exclusão e desafios para inserção econômica na produção de leite em Santa Catarina. Informações Econômicas, São Paulo, v. 35, n. 1, jan. 2005, p. 22 a 36.

FIGUEIRA, S. R.; BELIK, W. Transformações no Elo Industrial da Cadeia Produtiva do Leite. In: Revista Cadernos de Debate, v. III. UNICAMP, 1999.

GOMES, A. L. Indicadores de eficiência de escala na produção de leite: um estudo de caso para produtores dos estados Rondônia, Tocantins e Rio de janeiro. Tese (Doutorado). Escola Superior de Agricultura "Luiz de Queiroz”. Universidade São Paulo, Piracicaba, 2006.

JANK, M. S.; GALAN, V. B. Competitividade do Sistema Agroindustrial do Leite. Relatório de Pesquisa: Escola Superior de Agricultura “Luiz de Queiroz” - USP- São Paulo, 1999.

LOOTTY, M.; SZAPIRO, M. Economias de escala e escopo. IN: KUPFER, D. E HANSENCLEVER L. (org). Economia industrial: fundamentos teóricos e práticos no Brasil. Rio de janeiro, 2002. Cap. 03, p. 43-70.

LOPES, P. F. Custos e escala na pecuária leiteira: um estudo nos principais estados produtores do Brasil. Dissertação (Mestrado). Programa de Pós-graduação em Administração em Dinâmica e Gestão de Cadeias Produtivas. Universidade Federal de Lavras, Lavras, 2006.

MEZZADRI, F. P. Análise da conjuntura agropecuária safra 2009/2010. SEAB. Departamento de economia rural. Disponível em: <www.seab.pr.gov.br>. Acesso em: 24 de janeiro de 2010.

PAES, S. M. Governança no Agronegócio: enfoque na cadeia produtiva do leite. Porto velho: EDUFRO, 2007.

SOUZA, J. B. L. Agricultura familiar e pecuária leiteira: um estudo dos assentamentos nos municípios de Peabirú e Quinta do Sol. Dissertação (Mestrado) - Universidade Estadual de Maringá, Maringá, 2010.

SOUZA, R. P. As transformações na cadeia produtiva do leite e a viabilidade da agricultura familiar: o caso do sistema Coorlac (RS). Dissertação (mestrado). Programa de Pós-Graduação em Desenvolvimento Rural da Faculdade de Ciências Econômicas da UFRGS, Porto alegre, $2007 \mathrm{a}$. 
SOUZA, T. T. R. Pagamento por qualidade do leite: um estudo sobre os Laticínios do Estado do Paraná. Dissertação (Mestrado em Economia). Programa de Pós-Graduação em Teoria Econômica da Universidade Estadual de Maringá. Maringá, 2007b. 